\title{
INTRODUCCIÓN AL CINE HISTÓRICO: EL COLOSAL
}

\author{
JUAN ANTONIO BARRIO BARRIO \\ Universidad de Alicante
}

\begin{abstract}
SUMARIO
1. El cine histórico: 1.1. El Kollossal norteamericano. 1.2. El colosal norteamericano rodado en Europa. 1.3. El colosal Europeo.- El cine histórico a través de una selección sucinta de títulos.- Selección bibliográfica.
\end{abstract}

\section{EL CINE HISTÓRICO}

El cine histórico ha encontrado en algunos temas dotados de atractivo cultural, histórico y popular a la vez, un filón que ha sabido explotar dentro de un estilo artístico en el que ha primado especialmente el espectáculo colorista y de masas por encima de un análisis riguroso. En la actualidad para la mayoría de la población, la principal fuente de conocimiento histórico es el medio audiovisual, el cine y la televisión ${ }^{1}$. De esta forma la antigüedad en general, pero muy especialmente los temas bíblicos, Roma y la Edad Media han sido los escenarios históricos que recreados por la industria del cine han transportado bajo una óptica muy peculiar a millones de espectadores de todo el mundo a las calles de Roma, al Egipto de los faraones, a la tierra Santa ocupada por los cruzados o a los escenarios de la

\footnotetext{
'R.A. Rosenstone, El pasado en imágenes: El desafio del cine a nuestra idea de la historia, Barcelona, 1997, p. 29.

"Anuario de Estudios Medievales", 29 (1999)
} 
vida y pasión de Cristo. Por tanto, es indudable que la transmisión del conocimiento general de la Historia y de fenómenos históricos muy señalados, viene condicionado por las imágenes recibidas a través del lenguaje cinematográfico por millones de espectadores de todo el mundo. En la elaboración de la película como medio de expresión artística y vehículo de entretenimiento de masas, desde que surge el proyecto de la misma hasta que se lleva a cabo el estreno, intervienen un elevado número de profesionales como el guionista, el director, los actores, el productor, los técnicos, especialistas, etc. Aunque últimamente existe una tendencia cada vez más extendida a situar la responsabilidad última y definitiva del resultado de la película en el Director, los críticos tienden a valorar además la participación del equipo. Precisamente la utilización abusiva en los títulos de crédito en las últimas grandes producciones del enunciado $A$...film (Una película de...) ha movilizado a los guionistas más prestigiosos de Hollywood contra lo que consideran una actuación abusiva por parte de los grandes directores en la personalización de la autoría de la obra. Todo lo anterior evidencia la enorme complejidad financiera, técnica y artística que implica la realización de un filme, lo que aleja al historiador de la posibilidad de utilizar un medio artístico y de divulgación tan importante en la fase directa de realización, salvo que sea contratado como guionista lo que a todas luces queda muy alejado de la realidad. De esta forma la primera evidencia que el historiador percibe del complejo mundo del cine, es que tiene que asistir como espectador pasivo a la contemplación del resultado de las obras del Séptimo Arte que abordan temas históricos. La participación del historiador como asesor histórico en la historia del cine ha sido francamente mínima y frecuentemente despreciada por los grandes especialistas como Cecil Bount de Mille que llego a lamentarse en más de una ocasión del dinero que dilapidaba en asesores históricos, que luego no le servían para nada.

Hay que admitir que desde sus orígenes el cine ha puesto en imágenes episodios destacados de nuestra historia. En muchos países los primeros films fueron históricos ${ }^{2}$. Los cineastas han escrito sobre la historia, utilizando el lenguaje cinético, al margen de los historiadores. También hay que reconocer que la comunidad científica histórica ha tendido a dar la espalda al medio cinematográfico como elemento de explicación y divulgación de la historia. Sólo en las tres últimas décadas ha surgido un interés

${ }^{2}$ R.A. Rosenstone, El pasado en imágenes, p. 18. 
entre algunos especialistas destacados como Marc Ferro ${ }^{3}$, Pierre Sorlin ${ }^{4}$ o Robert A. Rosentone $e^{5}$ aunque desde diferentes presupuestos, en la utilización del cine como vehículo de explicación de la historia, e incluso como vía alternativa para escribirla. Aires de renovación que han llegado también aunque con más retraso y menos empuje a nuestro país ${ }^{6}$, donde ha ido surgiendo en la Universidad española la especialidad de "Historia del Cine", dentro de los Departamentos universitarios de Historia Contemporánea e Historia del Arte, así como en el ámbito cada vez más especializado del sector de la imagen.

El artículo como índica su título es una aproximación al cine histórico, desde el prisma de un historiador, como herramienta de trabajo para abordar las cuestiones planteadas anteriormente y que incluye como apéndice una selección sucinta de algunos títulos señeros del cine histórico, con especial atención hacia el cine de temática medieval.

La inspiración sobre la que se ha nutrido básicamente el cine histórico, ha sido o bien las fuentes originales interpretadas libremente como en Los Diez Mandamientos sobre textos bíblicos o El Cid donde en parte se utilizan textos sobre los que sustentaron las leyendas cidianas, como el Cantar, y otros posteriores como Las Mocedades del Cid de Guillén de Castro o El Cid de Corneille. Parte de la vasta producción literaria de un autor tan prestigioso como Shakespeare ha sido con cierta frecuencia fuente de inspiración para el cine o la pequeña pantalla, en distintas versiones y adaptaciones como Otelo, Hamlet, Ricardo III, Enrique V, Romeo y Julieta, Julio Cesar, El sueño de una noche de verano o Mucho ruido y pocas nueces. La primera versión cinematográfica de Julio Cesar se realizo en 1908 por William R. Ranous. En este caso nos encontramos con una obra magistral que ha dado pie a algunas excelentes películas con ambientación histórica y con un marchamo de qualité que las han alejado de las grandes superproducciones y del cine colosalista.

Otra de las fuentes de que se ha surtido el cine histórico ha sido la novela histórica, corriente literaria siempre muy popular y que tuvo su eclosión en el romanticismo que buscó en la Historia las causas que

\footnotetext{
${ }^{3}$ M. Ferro, Historia Contemporánea y cine, Barcelona, 1995.

${ }^{4}$ P. SORLIn, Sociología del cine. México, 1985: La storia nei film, Firenze, 1984.

${ }^{5} \mathrm{R}$.A. ROSENSTONE, El pasado en imágenes. cit.

"Vid. J.M. a Caparrós Lera, 100 películas sobre Historia Contemporánea, Madrid, 1997.
} 
justificaban los nacionalismos y las revoluciones burguesas ante el Antiguo Régimen que agonizaba. En este contexto político y cultural se produjo el apogeo de la novela histórica, que vive recientemente uno de sus periodos de mayor gloria. En plena eclosión del Romanticismo su creador fue Walter Scott (1771-1832), novelista, poeta, historiador y biógrafo escocés y una de las más prominentes figuras del romanticismo inglés. Algunos de sus relatos han sido llevadas al cine, como Rob Roy (1818), Ivanhoe (1820) y Quentin Durward (1823). El romanticismo de Scott ha sido definido como conservador y el objetivo de sus novelas era alimentar la fantasía de sus lectores sin provocar inquietudes ni trastornos ${ }^{7}$. El cine ha elegido también las novelas con ambientación histórica de otro escritor escoces del siglo XIX Robert Louis Stevenson (1850-1894), como La isla del tesoro (1883), La flecha negra (1888) y El señor de Ballantree (1889). Entre los escritores decimonónicos también hay que mencionar a Alejandro Dumas con clásicos como Los tres mosqueteros (1844), El conde de Montecristo (1844) y La Reina Margot, que han sido trasladadas a la pantalla grande. Destacar también otras novelas históricas llevadas al celuloide como Ben-Hur, Quo Vadis, Faraón, El nombre de la Rosa, etc. Hay que recordar que la visión de la Edad Media forjada por los románticos era apasionada en exceso, llena de héroes, de cruzadas, de caballeros y de maravillosas leyendas. Precisamente el cine ha encontrado en la visión de esta época de "oscuridad" monjes, castillos, etc. un atractivo para las típicas producciones de héroes y aventuras".

Así pues, la reconstrucción de la Historia está inmersa en los problemas de la sociedad que le ha tocado vivir a los historiadores y escritores y por tanto el producto de su trabajo siempre se verá influenciado por las corrientes de pensamiento que le son contemporáneas. Siendo "un producto cultural e ideológico del mundo occidental en un momento de su devenir" ${ }^{10}$. De ahí la necesidad de reescribir continuamente la Historia, ya que cada generación le hace preguntas diferentes. Por otra parte la concatenación de los hechos históricos no conducen siempre a los mismos

\footnotetext{
${ }^{7}$ M. Cranston, El romanticismo, Barcelona, 1997, p. 107.

${ }^{8}$ Sobre esta visión peyorativa que asocia la idea de "tiempos oscuros" al medievo, vid. J. HeERS, La invención de la Edad Media, Barcelona, 1995.

${ }^{9} \mathrm{~V}$. AtTolini, Immagini del Medioev'o nel cinema, Bari, 1993.

${ }^{10}$ R.A. Rosenstone, El pasado en imágenes, cit. p. 19.
} 
resultados, pues la libertad del hombre, objeto y sujeto de la Historia, junto con la compleja red de causalidades que actúan sobre el acontecer humano, originan un enorme abanico de posibilidades ante cualquier tipo de predicción $^{11}$.

En esta línea el cine al asumir tareas de historia relata, explica e interpreta el pasado, pero utilizando un lenguaje muy diferente y expresando cosas muy distintas de las que figuran en los libros de Historia y con un lenguaje narrativo más ágil y sin tener que estar tan sujeto al rigor histórico como el libro escrito por un historiador ${ }^{12}$. Por otra parte, esta práctica no conduce necesariamente a una transgresión de la verdad histórica, aunque hay ocasiones en las que se altera sustancialmente la historia. El cine al reescribir el pasado utiliza procesos de condensación, compresión, alteración, simbolización y metáfora' ${ }^{13}$.

La continua reinterpretación de la Historia realizada por la historiográfica académica ${ }^{14}$ y por el cine aparece, por tanto, en estrecha relación con las necesidades de cada presente ${ }^{15}$. Por eso, en la búsqueda de respuestas en el pasado, nada conduce a preguntarnos cual puede ser el punto de vista más adecuado, ya que cada uno de ellos fue el único posible para la generación que lo adoptó. Al mismo tiempo, el historiador ha de hacer el esfuerzo de situarse en la posición de las generaciones pasadas, pues cada hombre, cada cultura, tiene el derecho a ser entendida e interpretada con objetividad desde su propio interior, desde su propio tiempo, peculiar y distinto, y sobre todo respetando su escala de valores. De esta forma el cine histórico como testimonio imperecedero de un hecho histórico y que deja huella en varias generaciones de espectadores, esta determinado por las circunstancias que envolvieron su realización ${ }^{16}$. Tenemos un ejemplo claro en una producción clásica como Enrique $V$ de Shakespeare llevada al cine en 1944 por Laurence Olivier y en 1989 por Kenneth Brannagh, resultando dos películas que utilizando la misma fuente literaria, presentan el mismo

\footnotetext{
"C. SÁnChez Albornoz, Ensayos sobre Historiologia. Historia y Libertad, Madrid, 1977. pp. 177 ss

${ }^{12} \mathrm{~V}$. AtTolini, Immagini del Medioevo, cit. p. 8.

${ }^{13}$ R.A. Rosenstone, La Historia en la pantalla; Ma.A. PAz Rebollo; J. Montero DíAZ(dirs.), Historia y cine: realidad, ficción y propaganda, Madrid, 1995, p. 16.

${ }^{14}$ A. SCHAFF, Historia y Verdad, Barcelona, 1973, pp. 321-333.

${ }^{15}$ R.A. Rosenstone, El pasado en imágenes, cit. p. 20.

${ }^{16}$ Ésta es la línea que ha defendido Pierre Sorlin. Vid. La storia nei film, Firenze, 1984.
} 
acontecimiento histórico la batalla de Azincourt de 1415 bajo dos puntos de vistas totalmente opuestos. El primero motivado por la necesaria propaganda política que los aliados querían transmitir a la población antes del desembarco en Francia. Por ello la guerra se presenta de forma triunfal. En la película de Brannagh rodada bajo condicionamientos muy diferentes, en una época en la que el mensaje pacifista es frecuente, el director mostro con toda su crudeza y realismo el horror de la guerra y de la muerte. Por tanto una misma fuente literaria, el mismo acontecimiento histórico genera dos películas que representan el momento histórico en el que han estado producidas $^{17}$. Más recientemente en la última producción que realiza una disección del desembarco de Normandía, Salvad al soldado Ryan (Spielberg, S. 1998) ${ }^{18}$, aunque su director asimila y retoma las secuencias más señaladas de producciones bélicas como La colina de los diablos de acero (Mann, A. 1957) y se recuerda El día más largo (1962) la obra que abordo con detalle documental el dia-D, su visión descarnada y extremadamente realista en escenas muy explicitas de la tragedia de la guerra, presenta como el ejemplo anterior una visión novedosa de uno de los desembarcos más filmados en la historia del Cine.

El cine histórico más conocido por el público y que más popularidad ha alcanzando es el "drama histórico" ${ }^{19}$ y que en su vertiente más grandiosa y popular ha sido incluido por los críticos en el genero del Kollossal ${ }^{20}$ y que ha abundado especialmente en la vertiente de espectáculo de entretenimiento y de masas en su doble acepción, ya que se utilizaban abundantes extras en el rodaje de las películas e iban dirigidas a un amplio público con el objetivo de alcanzar en taquilla recaudaciones elevadas.

Dado que una parte sustancial del cine histórico entronca perfectamente dentro de esta concepción colosalista, voy a realizar una breve aproximación al Kollossal uno de los géneros más populares entre los aficionados al séptimo arte.

Sobre el nacimiento del genero Antonio José Navarro en un artículo de la revista Dirigido afirmaba tajante que "es un invento genuinamente

\footnotetext{
${ }^{17}$ N. BOU; X. PÉREZ, Cinematografía y actividades didácticas. Casos concretos en geografía e historia, "Íber", 11 (enero, 1997), p. 33.

${ }^{18}$ M. Robbins, Amarga victoria, “Dirigido”, 271 (Septiembre 1998), pp. 26-28.

${ }^{19}$ R.A. Rosenstone, El pasado en imágenes, p. 33.

${ }^{20}$ Utilizo la acepción aceptada por los críticos e historiadores de cine. Vid. C. LosILLA, El Kollossal de Hollywood. La industria como espectáculo, "Dirigido", 239 (Octubre 1995), p. 42.
} 
europeo, italiano para más señas". La primera referencia que cita es Gli ultimi giorni di Pompei de Luigi Maggi de $1908^{21}$. En la misma publicación su compañero Carlos Losilla sin realizar una aseveración del tal rotundidad si que aporta datos elocuentes sobre el nacimiento del colosal en Hollywood al citar la Passion de J.L. Vincent (1897) o versiones de "espectaculares" clásicos como Julius Caesar (1908) de W.R. Ranous ${ }^{22}$. El reciente centenario del cine se ha prestado a debates y propuestas para reivindicar todas las posibles paternidades y cunas en torno al séptimo arte. No es mi intención entrar en esta discusión y en todo caso queda claro que hubo una eclosión paralela del cine histórico espectacular en Estados Unidos y en Europa, lo que por otra parte y como han demostrado ambos autores dio lugar al desarrollo de dos modalidades distintas de entender el genero. En Estados Unidos primando el espectáculo y el factor industrial en detrimento del rigor y de la calidad artistica del producto. En Europa y en un continente con una tradición cultural y artística de varias centurias, se ha impuesto "un feroz ejercicio de autoafirmación cultural" ${ }^{23}$ e impera el concepto de autor por encima de valores industriales o crematísticos, lo que por otra parte ha dado lugar a resultados muy desiguales de taquilla y de critica.

\subsection{El "Kollossal" norteamericano}

El cine kollossal tiene sus orígenes en Italia y Hollywood, aunque será en Estados Unidos donde alcance su mayor desarrollo. Esta asociado a las grandes producciones con elevado presupuesto, grandes estrellas, escenarios colosales y abundantes extras. Baste recordar el ejemplo del episodio babilónico de Intolerancia (1916) de Griffith para que nos hagamos una idea del inicio de una concepción del cine, que tuvo su apogeo entre los años cincuenta y sesenta, coincidiendo con el auge del tecnicolor y el uso del CinemasCope que permitía rodar planos más grandiosos que las películas tradicionales de $35 \mathrm{~mm}$. Además hay que destacar también que la elección de un tema con cierto prestigio cultural - verbigracia las historias bíblicascon antecedentes literarios y con una definida importancia histórica o

\footnotetext{
${ }^{21}$ A.J. NAvarro, Cultura, drama y sofisticación, "Dirigido", n” 241 (Noviembre, 1995), pp. 52-65. (p. 52).

${ }^{22}$ C. Losilla, El Kollossal de Hollywood, pp. 34-35.

${ }^{23}$ A.J. NAVARRo, Cultura, drama y sofisticación, cit. p. 52.
} 
sociológica, son factores decisivos a la hora de catalogar una película dentro de la categoría de Kollossal. Algunas de las características que luego serían consustanciales a este estilo fílmico se fueron definiendo en las primeras décadas del siglo XX con la realización de los primeros colosales de la historia del cine en Hollywood. Como apunta Carlos Losilla Julius Caesar (William R. Ranous, 1908), Cleopatra (Charles L. Gaskill, 1912), Ben-Hur (Sidney Olcott, 1913) y La batalla de Gettysburgh (Thomas H. Ince, 1914), son algunos de los títulos que prefiguraron estos elementos esenciales: la descripción por encima de la narración, la recreación en el plano y en la escena antes que en el conjunto del film, la potenciación de los volúmenes y de los colores o de los tonos del gris en detrimento de la movilidad del encuadre, etc. La Biblia y la Antigüedad romana junto a la Edad Media fueron los principales temas y escenarios históricos de los colosales producidos en Hollywood ${ }^{24}$. Otra de las cuestiones fundamentales que se perciben al analizar las raíces del Kollossal en Hollywood en las primeras décadas del siglo XX, es que no era un genero propiamente dicho ya que a pesar de tener unos rasgos claramente definidos, termina abarcando a varios de los géneros clásicos como el melodrama, el Western, el film de guerra y lógicamente el cine histórico y la especialidad del cine bíblico. Lo que distinguía al Kollossal de otras películas que abordasen estos temas es su grandiosidad.

Hemos hablado de Griffith y hay que destacar que es el padre del Kollossal en Hollywood ya que puso los cimientos del mismo, al fijar con absoluta precisión las claves de una síntesis narrativa propiamente cinematográfica que sus sucesores se limitaran a perfeccionar. Con anterioridad al maestro lo habitual era la superposición de una serie de cuadros vivientes, en una auténtica teatralización pictórica. Griffith en tres películas ${ }^{25}$ y de forma sucesiva y gradual fijo las bases del lenguaje moderno cinematográfico al establecer una coherencia narrativa y lógica entre un plano y el siguiente y también con los bloques de secuencias que gracias al montaje permitían la alternancia de planos y escenas, acabando con el hieratismo teatral del cine anterior.

Uno de los más destacados continuadores del Kollossal es Cecil Blount de Mille que se convirtió en uno de los directores paradigmáticos en

\footnotetext{
${ }^{24}$ C. Losilla, El Kollossal de Hollywood, pp. 32-51.

${ }^{25}$ Judith de Betulia (1914), El nacimiento de una nación (1914) e Intolerancia (1916).
} 
el colosalismo asociando su carrera, su continuidad y su éxito a una de las compañías más importantes, la Paramount. Fue el renovador del colosal desde los años veinte con Los Diez Mandamientos (1923), Rey de Reyes (1927), continuando su trayectoria triunfal en los treinta con películas históricas como El signo de la cruz (1932), Cleopatra (1934), suponiendo ambas las "más mastodónticas recreaciones de la antigua Roma realizadas hasta el momento" 26 , un acercamiento al tema medieval predilecto de Hollywood: Las Cruzadas (1935), un western Kollossal como Buffalo Bill (1936) o Corsarios de Florida (1938) y Unión Pacífico (1939) en las que se mantienen las líneas básicas: gigantismo, larga duración de las películas superior a dos horas, numerosos figurantes y secundarios, escenarios fastuosos, temas de interés, al mismo tiempo, humano, histórico, incluso filosófico y religioso ${ }^{27}$. Sin embargo en los años cuarenta a pesar de continuar con en la misma línea, el Kollossal quedo reducido a su mínima expresión, a una especie de mini Kollossal por diversos factores entre los que hay que mencionar la austeridad que impuso el conflicto bélico y la necesidad de un cine que reflejase otros problemas con más intimismo ${ }^{28}$. Películas como Juana de Arco (Victor Fleming, 1948) suponen una ruptura con las realizadas en la década anterior, mientras que un año después Sansón y Dalila de De Mille esta anunciando el apogeo del Kollossal en los felices cincuenta. Terminada la guerra y con la alegría económica y vital que estallo en Estados Unidos, la televisión se convirtió en un serio competidor del cine. La respuesta a esta nueva realidad fue el auge y apogeo del cine colosal en los años cincuenta con la introducción del CinemasCope y el rodaje de varias superproducciones en las que no se escatimaba en gastos a la hora de incluir el mayor número de figurantes y los escenarios más espectaculares, con producciones en las que predominaba un cierto barniz cultural afín a la ideología imperante del "sistema de vida americano" y en el contexto de guerra fría y tras la depuración política iniciada por el Senador McCarthy y más conocida como la famosa "caza de brujas". En este periodo se rodaron obras clásicas como La túnica sagrada (Henry Koster, 1953) la primera película rodada en CinemasCope, Quo Vadis, (Mervin Le Roy, 1954), Los Diez Mandamientos (Cecil B. de Mille, 1965),

\footnotetext{
${ }^{26}$ C. Losilla, El Kollossal de Hollywood, p. 37.

${ }^{27}$ J.L. PASSEK, (Dir.), Diccionario del Cine, Madrid, 1991, p. 209.

${ }^{28}$ C. Losilla, El Kollossal de Hollywood, cit., p. 40.
} 
Ben-Hur (William Wyler, 1959), Sinuhé el egipcio (Michael Curtiz, 1954) y Tierra de faraones (Howard Hawks, 1955) ambas ambientadas en el Egipto de los faraones.

Los años sesenta contemplan por una parte la lenta decadencia de las superproducciones y por otra una saludable humanización y personalización del producto resultante, surgiendo como prefiguración del futuro una política de autor que abría nuevos horizontes y patente en filmes como Espartaco (1960) de Stanley Kubrick y con guión de Donald Trumbo. Hay que resaltar también que Hollywood arrincono en esta década los temas bíblicos y de romanos y los substituyó por películas bélicas, dadas las circunstancias por las que atravesaba Estados Unidos en ese momento. Citar por ejemplo Los cañones de Navarone (1961), El día más largo (1962), Operación Crossbow (1965) o El desafío de las águilas (1969) exaltación patriótica centrada en los éxitos de la victoria aliada en la Segunda Guerra Mundial. Las películas de romanos de De Mille habían pasado a la historia y Cleopatra (1963) uno de los intentos más osados por reverdecer aquellos tiempos gloriosos termino en su sonoro fracaso y estuvo a punto de acabar con la trayectoria de un gran director. Con un coste final de 44 millones de dólares que nunca se recuperaron simbolizaba el fin de la época clásica del colosal del Hollywood clásico. Tras estos intentos de exaltación patriótica y la bancarrota del genero con Cleopatra, las películas colosales de la siguiente década se pueden resumir en un tema: la catástrofe como argumento y como símbolo de autofustigación por parte de Hollywood con Tora, tora, tora (R. Fleischer, 1970), La aventura del Poseidon (1972), El coloso en llamas (1975), Terremoto (1975) y Aeoropuerto 75 (1975), mientras que la emblemática La guerra de las galaxias (1975) anuncia lo que va a ser el patrón de las próximas décadas la exaltación de la tecnología, siendo así el primer gran éxito del Kollossal-tecno en expresión de Carlos Losilla. Precisamente su director George Lucas y su amigo Steven Spielberg son los artífices del posmodernismo de los ochenta y del actual Kollossal de Hollywood donde se combinan la mezcla de géneros con la más avanzada tecnología. Junto a esta línea que ha tenido sus seguidores y malos imitadores ha surgido otra que pretende ser más seria, abordando "grandes temas" con un barniz supuestamente "intelectual, digno y progresista" ${ }^{29}$. con resultados como

\footnotetext{
${ }^{29}$ Estoy siguiendo en las últimas líneas básicamente la excelente reflexión que presenta Carlos Losilla en El Kollossal de Hollywood, cit.
} 
Rojos (1981), Amadeus (1984), Valmont (1989) El último emperador o Bailando con lobos (1990) y más recientemente Braveheart (1995). Las últimas producciones de los noventa como Titanic (J. Cameron) y Amistad (S. Spielberg), aventuran una nueva vía en el cine norteamericano, el cine "mamut" con filmes de más de 150 minutos $^{30}$ y con un espectacular despliegue de medios tecnológicos.

\subsection{El colosal norteamericano rodado en Europa}

Las dificultades financieras de los grandes estudios, los altos costes de producción y la necesidad de seguir compitiendo con la televisión, fuerzan el cambio de dirección en el rodaje de algunos colosales por las grandes compañías norteamericanas que ponen sus ojos en Europa y las enormes y fructíferas posibilidades de ofrecen países como Italia y España. Aunque la práctica de rodar en Europa se había iniciado en Inglaterra con la producción de algunas películas con trasfondo histórico en los años cincuenta como La rosa negra (H. Hataway, 1950) ambientada en la Edad Media con un tema que ha sido atractivo para el cine como el conflicto entre sajones y normandos en Inglaterra o La reina virgen (G.Sydne, 1953), las grandes superproducciones se rodaron sobre todo en los estudios Cineccità de Roma (Ben-Hur) o los estudios Bronston en Madrid ( $E l \mathrm{Cid}$ ).

La elección de España e Italia venía determinada por la mano de obra barata, las facilidades dadas por los respectivos gobiernos para las inversiones económicas, la climatología; la posibilidad de encontrar optimas localizaciones, buenos estudios y técnicos de calidad avalaban el desembarco de los grandes estudios en Europa. En Italia y en los estudios Cineccità se rodaron superproducciones de la importancia de Ben-Hur (Wyler, W. 1959), Cleopatra (Mankiewicz, J.L. 1963), La Biblia (J. Huston, 1965) y La historia más grande jamás contada (G. Stevens 1965). El rodaje de colosales de Hollywood en España se inició en los años cincuenta con películas de gran presupuesto y con grandes estrellas como Orgullo y pasión (S. Kramer, 1957) o Salomón y la reina de Saba (K. Vidor, 1959). En los años sesenta lo más destacado fue la creación del Imperio Bronston que permitió la realización de títulos como $\mathrm{El}$ Cid, Rey de reyes, La caída del Imperio romano, 55 días en Pekín, etc.

\footnotetext{
${ }^{30}$ V. Molina FoIx, Llega el cine 'mamut', "El País” (26 de enero de 1998), p. 35.
} 
Al mismo tiempo y sobre todo en Italia la ejecución de producciones de menor relevancia económica con la participación de directores y actores norteamericanos con el complemento de directores italianos de la segunda unidad y actores europeos y con la elección de temática histórica con ambientación especialmente en la antigüedad, permitió el desarrollo dentro del cine histórico de un subgénero "El peplum" que dio títulos de indudable calidad como Helena de Troya (R. Walsh-S. Leone, 1955), El león de Esparta (R. Maté, 1961), La batalla de Marathon (J. Tourneur-M.Bava, 1959), Esther y el rey (R. Walsh-M.Bava, 1960), o Sodoma y Gomorra (R. Aldrich-S.Leone, 1962), en las que participaron norteamericanos como J. Tourneur o R. Walsh e italianos como Sergio Leone o Mario Bava ${ }^{31}$. Pero debido al abrumador éxito internacional del peplum italiano, se produjo entre los años cincuenta y principios de los sesenta una avalancha de producciones en las que, frente a la dignidad de las citadas anteriormente, predominaron las de bajo presupuesto, basadas en guiones deficientes, con pésima dirección e interpretación y rodadas con escasos medios técnicos y con la precipitación que implicaba abastecer la voracidad de un mercado que reclamaba este tipo de películas. Por citar sólo a las más destacadas recordar Hércules (1957), Cartago en llamas (1959), El Coloso de Rodas (1960) o Constantino el Grande $(1962)^{32}$.

\subsection{El colosal Europeo}

En Europa se ruedan las primeras películas espectaculares con trasfondo histórico en Italia ${ }^{33}$. Frente al control que ejercía la industria en las producciones norteamericanas, en las europeas en líneas generales el realizador asumía un papel de mayor envergadura. Hay, por tanto, una mayor autoría personal en el acabado del producto en la dinámica ya reseñada de autoafirmación cultural. De todo ello son una muestras títulos como Napoleón de Abal Gance, La leyenda de los Nibelungos de Fritz Lang, Alexander Nevski, Iván el terrible y La conjura de los boyardos de

\footnotetext{
46-61.

${ }^{31}$ Q. CASAS, El Kollossal americanos en Europa, "Dirigido”, 240 (Noviembre, 1995), pp.

${ }^{32}$ A.J. NAVARro, Cultura, drama y sofisticación, p. 62. cit.

${ }^{33}$ Básicamente sigo el excelente artículo de A.J. NAVARRO, Cultura, drama y sofisticación,
} 
Eisenstein, Hamlet o Enrique $V$ de Laurence Olivier y El Gatopardo de Visconti, por poner sólo algunos ejemplos.

Las principales características que enmarcan el Kollossal europeo y lo diferencian del norteamericano se pueden sintetizar en:

-Predilección por las grandes minorías frente al cine de consumo masivo procedente de EEUU.

-El cuidado al seleccionar sus fuentes de inspiración narrativa, verbigracia literatura de calidad, como la de Shakespeare, El Gatopardo de Lampedusa, Faraón de Prus, Doctor Zivagho de Pasternak, El Satyricon de Petronio, Guerra y Paz de Tolstoi, Becket, o el honor de Dios de Anouith, etc.. Comparese lo anterior con referencias del fuste de Sinuhé el Egipcio, Quo Vadis o Ben-Hur, e incluso las de un autor como tan prestigioso como Scott, pero cuya visión "romántica" de la historia resultaba un tanto trasnochada cuando se rodaron las películas. Lo peor de todo es que esta imagen del medioevo, de las cruzadas, etc., ha calado en una parte importante del publico y son mitos que luego cuesta mucho derribar. Esta elección se deja sentir en el colosal europeo en el propio lenguaje fílmico expresado, fruto también de siglos de literatura, pintura, teatro, música, arquitectura, filosofía, etc. Poso intelectual y cultural del que carece la sociedad norteamericana.

- Un exquisito cuidado en la traslación a imágenes de la historia narrada y una participación de los referentes de la cultura europea que son integrados en el filme, lo que se ha traducido en una cuidadosa puesta en escena y una esmerada reconstrucción del ambiente de una época determinada, cuyo ejemplo paradigmático y siempre citado es el de un director europeo como Visconti, exponente y reflejo de todo lo anterior y que en la obra maestra por antonomasia, El Gatopardo (1962) tiene su mayor logro y expresión y en la que la reconstrucción alcanza casi un rigor arqueológico.

-A diferencia de sus homónimas norteamericanas las películas europeas encierran algún mensaje ético o político que supera la tradicional visión superficial que se ofrece en las películas norteamericanas. Comparese por ejemplo $\mathrm{El} \mathrm{Cid} d^{34}$ con obras inglesas como Zulú donde se realiza un análisis de lo absurdo del conflicto bélico que enfrento a ingleses y zulúes en 1879 y la posición ante el mismo de los combatientes en función de su

${ }^{34}$ J.A. BARrio BARrio, El Cid de Anthony Mann a través del cine histórico y la Edad Media, La didáctica de la Historia a través del Cine (en prensa). 
extracción social. Este enfrentamiento interclasista esta totalmente ausente en El Cid, a pesar de que como ha señalado Francisco Rico el propio Cantar ya expresa un enfrentamiento clasista entre Rodrigo Díaz de Vivar un infanzón que pertenece a la nobleza emergente y aprovecha las extraordinarias expectativas de enriquecimiento que ofrece la reconquista y la repoblación $^{35}$, frente a personajes como García Ordóñez representante de la alta nobleza territorial ${ }^{36}$. Por otra parte ese deseo de crítica trascendental del colosal europeo no exime a las películas de la vertiente lúdica del espectáculo. En todo caso hay una clara diferencia entre películas ligeras y entretenidas como las norteamericanas El Cid, Los Diez Mandamientos, Ivanhoe, etc y las más densas y menos comerciales como Faraón, Iván el Terrible, Becket, Satyricon, etc., en su variante europea.

\footnotetext{
${ }^{35}$ Sobre este proceso vid. M.A. LADERo QuESADA, Historia de España fundada por $R$. Menéndez Pidal, IX: La reconquista y el proceso de diferenciación política (1035-1217), Madrid, 1998.

${ }^{36}$ F. RiCo, Poesía e Historia del "Cantar del Cid», Cantar del Mio Cid, Barcelona, 1997, pp. $20-21$.
} 


\section{EL CINE HISTÓRICO A TRAVÉS DE UNA SELECCIÓN SUCINTA DE TÍTULOS ${ }^{1}$}

La filmografía que ofrecemos como una primera aproximación al cine histórico es una selección sucinta de títulos, realizada por el autor, en la que se han incluido las principales obras del colosal, además de referencias destacadas del cine histórico atendiendo a criterios de calidad artística y rigor histórico. He optado por una división cronológica sobre la periodización clásica de la Historia. Han primado los títulos dedicados al medioevo. Los filmes van ordenado en cada época histórica por orden cronológico de realización ${ }^{2}$. La lista no pretende ser exhaustiva y es simplemente un breve repaso a títulos esenciales para entender la relación que existe entre el Cine y la Historia.

\section{Prehistoria y Antigüedad}

Julius Caesar (William R. Ranous, 1908)

Gli ultimi giorni di Pompei (L. Maggi, 1908)

Cleopatra (Charles L. Gaskill, 1912)

Ben-Hur (Sidney Olcott, 1913)

Cabiria (G. Pastrone, 1914)

Intolerancia (Grifith 1916) (Episodio de Babilonia)

Los Diez Mandamientos (Mille, C.B. 1923)

Be-Hur (Niblo, F. 1926)

Rey de Reyes (Mille, C.B. 1927)

El signo de la cruz (Mille, C.B. 1932)

\footnotetext{
'Para la elaboración de esta filmografía, las fuentes utilizadas son múltiples y han ido desde los fondos de la videoteca del autor, pasando por la consulta de diccionarios especializados, revistas y alguno de los títulos incluidos en el apéndice bibliográfico. Han sido de gran utilidad las fuentes de Internet como la Medieval Sourcebook: Medieval movies. Version 3.5 (Paul Halsall, 1997-1998) (http://www.fordham.edu/halsall/medfilms.html) o la Internet Movie Database (http://us.imdb.com).

${ }^{2} \mathrm{He}$ incluido entre paréntesis el nombre del director y la fecha oficial de realización de cada película. Sobre la fecha de realización o estreno de un filme hay criterios dispares entre la información recogida en la Medieval Sourcebook: Medieval Movies. Version 3.5 (Paul Halsall, 1997-1998) y la que ofrecen algunas publicaciones especializadas. He optado por la fecha que ofrezca menos dudas y que sea la referencia más utilizada por los especialistas, especialmente los datos incluidos en J.L. PASSEK (Dir.) Diccionario del Cine.
} 
Cleopatra (Mille, C.B. 1934)

La túnica sagrada (Henry Koster, 1953)

Quo Vadis ? (Mervin Le Roy, 1954)

Sinuhé el egipcio (Michael Curtiz, 1954)

Tierra de faraones (Howard Hawks, 1955)

Salomón y la reina de Saba (K. Vidor, 1959).

Ben-Hur (Wyler, W. 1959)

Espartaco (Kubrick, S. 1960)

Rey de Reyes (Ray, N. 1961)

Barrabás (Fleischer, R. 1962)

Sodoma y Gomorra (Aldrich, R., y Leone, S. 1962),

Cleopatra (Mankiewicz, J.L. 1963)

La caída del Imperio romano (Mann, A. 1964)

La historia más grande contada (Stevens, G. 1965)

La Biblia(Huston, J. 1965),

Los Diez Mandamientos (Mille, C.B,. 1965)

La invasión de los Barbaros (Siodmak, R., 1968)

Satyricon (F. Fellini, 1969)

Los Hechos de los Apóstoles (Rossellini, R. 1969. TV)

Faraón (J. Kawalerowicz, 1970)

Sócrates (Rossellini, R. 1971. TV)

La vida de Brian (Jones, T. 1979)

Caligula (Franco Rossellini, 1980)

En busca del fuego (J-J. Annaud, 1981)

\section{Medioevo}

Intolerancia (Grifith 1916) (Episodio Medieval)

La muerte de Sigfrido y La venganza de Krimilda (F. Lang, 1923 y 1924)

La pasión de Juana de Arco (Dreyer, C. 1928)

Las Cruzadas (Mille, C.B. 1935)

Condottieri (Kingler, W., Trenker, L. 1937)

Alexander Nevski (S. Einsestein, 1938)

Las aventuras de Marco Polo (Mayo, A. 1938)

Robin de los bosques (Curtiz, M. 1938)

Enrique V (L.Olivier, 1944)

Ricardo III (L.Olivier, 1944)

Du Guesclin (De Latour, B. 1948)

Juana de Arco (Victor Fleming, 1948)

Macbeth. (Welles, O. 1948)

Rashomon (Kurosawa, A. 1950) 
Ivanhoe (Thorpe, R. 1952)

El príncipe valiente (Hathaway, H. 1954)

Teodora (Freda, R. 1954)

Atila, rey de los Hunos (Sirk, D. 1954)

Los caballeros del rey Arturo (Thorpe, R. 1954)

El Talismán (Butler, D. 1954)

Los siete samurais (Kurosawa, A. 1954)

Aventuras de Quintín Durward (Thoper, R. 1955)

Lady Godiva (Lubin, A. 1955)

El Septimo Sello (Bergman, I. 1956)

Los Vikingos (Fleischer, R. 1958)

El manantial de la doncella (Bergman, I. 1960)

El Cid (Mann, A. 1961)

Constantino el grande (De Felice, L. 1961)

Los Mongoles (De Toth, A. 1961)

Saladino (Chahine, Y. 1963)

Becket (Glenville, P. 1964)

Simón del desierto (Buñuel, L. 1965)

El señor de la guerra (Schaffner, F.J. 1965)

Los 100 caballeros (Cottafavi, V. 1965)

Genghis Khan (Levin, H. 1965)

Andrei Rublev (Tarkovsky, A. 1966)

Francesco d' Assisi (Cavani, L. 1966)

La Armada Brancaleone (Monicelli, M. 1966)

Campanadas a Medianoche (Welles, O. 1966)

Camelot (Logan, J. 1967)

El león en invierno (A. Harvey, 1968)

Romeo y Julieta (Zeffirelli, F. 1968)

Alfredo el Grande (C. Donner, 1969)

Paseo por la Vida y la Muerte (Houston, J. 1969)

Galileo (Cavani, L. 1969)

Brancaleone en las Cruzadas (Monicelli, M. 1970)

El Decamerón (Passolini, P.P. 1970)

Los cuentos de Canterbury (Passolini, P.P. 1971)

Lancelot du Lac (Bresson, R. 1974)

Los caballeros de la tabla cuadrada y sus locos seguidores (Jones, T. 1974)

Robin y Marian (Lester, R. 1976)

Mahoma, el mensajero de Díos (Akkad, M. 1976)

Perceval (Rohmer, E. 1978)

Kagemusha (Kurosawa, A. 1980)

Excalibur (J. Boorman, 1981) 
La conquista de Albania (Ungría, A. 1983)

Ran (Kurosawa, A. 1984)

El nombre de la Rosa (Annaud, J.J. 1986)

La pasión de Beatriz (Tavernier. B. 1987)

Daniya, Jardín del Harén (Mira, C. 1987)

Erik el Vikingo (Jones, T. 1989)

Enrique V (Brannagh, K. 1989)

Francesco (Cavani, L. 1989)

Al Andalus (Tarruella, A. Oriol, J. 1989)

Hamlet (Zeffirelli, F. 1990)

Eduardo II (Jarman, D. 1991)

Robin Hood (Irvin, J. 1991)

Robin Hood, principe de los ladrones (Reynolds, K. 1991)

Braveheart (Gibson, M. 1995)

\section{Edad Moderna}

Intolerancia (Grifith 1916) (Episodio sobre la Francia Hugonote. La Masacre de San Bartolome)

La Kermesse heroica (Feyder, J. 1935)

Rembrandt (Korda, A. 1936)

Corsarios de Florida (Mille, C.B. 1938)

La reina Cristina de Suecia (Mamoulian, R. 1933)

El Capitán Blood (Curtiz, M. 1935)

La Kermesse heroica (Feyder, J. 1935)

Iván el Terrible y La conjura de los Boyardos (S. Einsestein, 1943-45)

Hamlet (L.Olivier, 1944)

El Capitán de Castilla (King, H. 1947)

Martin Luther (Pichel, I. 1953)

El tormento y el éxtasis (Reed, C. 1965)

Un hombre para la eternidad (Zinnemann, F. 1966)

La toma del poder de Luis XIV (Rossellini, R. 1967. TV)

Ana de los 1000 días (Jarrot, Ch. 1969)

Cromwell (K. Hughes, 1970)

Aguirre, la cólera de Dios (Hergoz, W. 1972)

Galileo (Losey, J. 1974)

Barry Lindon (Kubrick, S. 1975)

La noche de Varennes (Scola, E. 1981)

El Retorno de Martin Guerre (Vigne, D. 1982)

Amadeus (Forman, M. 1984)

Revolución (Hudson, H. 1985) 
La Misión (Joffé, R. 1986)

Caravaggio (Jarman, D. 1986)

Esquilache (Molina, J. 1988)

Valmont (Forman, M. 1989)

Cyrano de Berberac (Rappeneau, J.P. 1990)

La batalla de los tres reyes (Ben Barka, S. 1990)

1492: La conquista del Paraíso (Scott, R. 1992)

Todas las mañanas del mundo (Corneau, A. 1992)

El último mohicano (Mann, M. 1992)

La Reina Margot (Chéreau, P. 1994)

Nostradamus (Christian, R. 1994)

Restauración (Hoffman, M.)

Ridicule (Laconte, P. 1996)

Elizabeth (Kapur, S. 1998)

\section{Mundo Contemporáneo}

La batalla de Gettysburgh (Thomas H. Ince, 1914)

El nacimiento de una nación (Grifith 1914)

La Huelga (Einsestein, S.M. 1925)

El gran desfile (Vidor, K. 1925)

El acorazado Potemkin (Einsestein, S.M. 1926)

Napoleón (A.Gance, 1927)

Octubre ((Einsestein, S.M. 1927)

Y el mundo marcha (Vidor, K. 1928)

Sin novedad en el frente (Milestone, L. 1930)

Adiós a las armas (Borzage, F. 1932)

Buffalo Bill (Mille, C.B. 1936)

Tiempos modernos (Chaplin, Ch. 1936)

La Gran Ilusión (Renoir, J. 1937)

La Marsellesa (Renoir, J. 1937-38)

Espoir. Sierra de Teruel. (Malraux, A. 1939)

Unión Pacífico (Mille, C.B. 1939)

Lo que el viento se llevó (Fleming, V. 1939)

Las uvas de la ira (Ford, J. 1940)

El gran Dictador (Chaplin, Ch. 1940)

Ciudadano Kane (Welles, O. 1941)

Sargento York (Hawks, H. 1941)

Roma, ciudad abierta (Rossellini, R. 1945)

El limpiabotas (Sica, V. 1946)

Los mejores años de nuestra vida (Wyler, W. 1946) 
Ladrón de Bicicletas (Sica, V. 1948)

El tercer hombre (Reed, C. 1949)

Surcos (Nieves, J.A. 1951)

¿ Viva Zapata! (Kaza, E. 1952)

¡ Bienvenido Mister Marshall! (Berlanga, L.G. 1952)

Muerte de un ciclista (Bardem, J.A. 1952)

La colina de los diablos de acero (Mann, A. 1957)

Orgullo y pasión (Kramer, S. 1957)

El puente sobre río Kway (D. Lean, 1957)

Senderos de Gloria ((Kubrick, S. 1957)

La gran guerra (Monicelli, M. 1959)

Éxodo (Preminger, O. 1960)

i Viva Italia! (Rossellini, R. 1960)

Los cañones de Navarone (J. Lee Thompson, 1961)

Vida difícil (Risi, D. 1961)

El día más largo (D.F. Zanuck y otros, 1962)

Lawrence de Arabia (D. Lean, 1962)

El Gatopardo (L. Visconti, 1962)

El proceso de Verona (Lizzani, C. 1962-63)

Zulú (C. Enfield, 1964)

Guerra y paz (S. Bondarchuk, 1964-67)

Operación Crossbow (1965)

55 días en Pekín (Ray, N. 1965)

El doctor Zivago (D. Lean, 1965)

La batalla de Argel (Pontecorvo, G. 1966)

El desafío de las águilas (B.G. Hutton, 1969)

La última carga (T. Richardson, 1969)

Patton (Schaffner, F. 1970)

Johnny cogió su fusil (Trumbo, D. 1970)

La hija de Ryan (D. Lean, 1970)

Tora, tora, tora (Fleischer, R. 1970)

Nicolás y Alejandra (Schaffner, F.J. 1971)

El delito Matteotti (Vancini, F. 1973)

Luis II de Baviera (Visconti, 1973)

El hombre que pudo reinar (Huston, J. 1975)

El viento y el león (Milius, J. 1975)

Novecento (Bertolucci, B. 1975)

El hombre de marmol (Wajda, A. 1976)

Apocalipsis Now (Coppola, F.F. 1979)

La puerta del cielo (M. Cimino, 1980)

Rojos (Beatty, W. 1981) 
Danton (Wajda, A. 1982)

Gandhi (Attenborough, R. 1982)

Los santos inocentes (Camus, M. 1984)

El color púrpura (Spielberg, 1985)

Platoon (Stone, O. 1986)

La chaqueta metálica (Kubrick, S. 1987)

El último Emperador (Bertolucci, B. 1987)

Walker (Cox, A. 1988)

Arde Misisipí (Parker, A. 1988)

Gloria (Zwick, E. 1989)

Nacido el 4 de Julio (Stone, O. 1989)

Bailando con lobos (Knoster, K. 1990)

i Ay Carmela ! (Saura, C. 1990)

JFK (Stone, O. 1991)

Malcom X (Lee, S. 1992)

La lista de Schindler (Spielberg, 1993)

Germinal (C. Berri, 1993)

La lista de Schindler (Spielberg, S. 1993)

Nixon (Stone, O. 1995)

Apollo 13 (Howard, R. 1995)

Tierra y libertad (Loach, K. 1995)

Salvad al soldado Ryan (Spielberg, 1998)

Les Misérables (August, B. 1998)

\section{SELECCIÓN BIBLIOGRÁFICA}

-Alegre, S., El cine cambia la historia, Barcelona, 1994.

-AtTolini, V., Immagini del Medioevo nel cinema, Bari, 1993.

-Bou, N.; PÉrez, X., Cinematografía y actividades didácticas. Casos concretos en geografía e historia, "Íber", 11 (enero, 1997), pp. 25-39.

-Bourget, J-L., L'histoire au cinéma: le passé retrouvé, París, 1992.

-CAPARRós Lera, J.Ma ${ }^{\mathrm{a}}$, 100 películas sobre Historia Contemporánea, Madrid, 1997.

-CASAS, Q., El Kollossal americanos en Europa, "Dirigido", 240 (Noviembre, 1995), pp. 46-61. 
-Carmona, R., Cómo se comenta un texto fílmico, Madrid, 1993.

-Ferro, M., Historia Contemporánea y cine, Barcelona, 1995.

-FloRes Auñón, J.C. El cine, otro medio didáctico. Introducción a una metodología para el uso del cine como fuente de las ciencias sociales, Madrid, 1982.

-Lagny, M., Cine e historia, Barcelona, 1997.

-Losilla, C., El Kollossal de Hollywood. La industria como espectáculo, "Dirigido", 239 (Octubre 1995), pp. 32-51.

-PASSEK, J.L. (Dir.) Diccionario del Cine, Madrid, 1991.

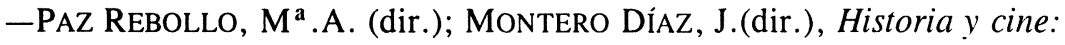
realidad, ficción y propaganda, Madrid, 1995.

-Rosenstone, R.A., El pasado en imágenes: El desafío del cine a nuestra idea de la historia, Barcelona, 1997.

-Sorlin, P., Sociología del cine, México, 1985.

-VV. AA., Cine, geografía e Historia, "Íber" 11 (enero, 1997).

-VV.AA., La Didáctica de la Historia a través del cine, Alicante (en Prensa).

-Wood, M., America in the Movies, Nueva York, 1975, vid. pp. 165-196.

\section{RÉSUMÉ}

Le cinéma historique représente actuellement une riche source d'information pour l'historien en tant que véhicule de connaissances et de divulgation de l'histoire. Nous pouvons ainsi nous servir de quelques moyens audio-visuels comme point de départ pour analyser la façon dont le cinéma reflète l'histoire.

Dans cet article, l'on fait une introduction du cinéma historique selon ses tendances les plus connues, celles du "Colosal", épitome cinematographique de la représentation de grands événements du passé recrées par l'industrie du cinéma à travers ses superproductions les plus connues. 


\section{SUMMARY}

Nowadays historical films represent a valuable source of information for historians. They can be used to communicate knowledge of the development of history. We can use audiovisual aids as a starting point in order to analyse the way the cinematographic industry reflects history.

In this article, we introduce historical films from the cinema and their most popular form, "Colossal", considered to be the reflection of the most important historical events represented by the cinema industry through the most popular mega-productions. 